\title{
Prácticas ARTísticas y espacios DE MEMORIA. Procesos de Transmisión
}

Artistic practices and Memory places. Transmission processes

\author{
Núria Ricart \\ nuriaricartulldemolins@ub.edu \\ Universidad de Barcelona
}

Noelia Paz

Universidad de Barcelona

RESUMEN: El objeto de este artículo es la reflexión en torno a las prácticas artísticas y su potencial en relación a la transmisión de las reivindicaciones sociales en procesos de transformación urbana y recuperación de la memoria en espacios de represión. Espacios que en numerosas ocasiones se hallan sujetos a transformaciones urbanas y nuevos usos. Nos interesa identificar las relaciones simbióticas entre prácticas artísticas contemporáneas, reivindicaciones sociales y espacios de memoria, observando el particular potencial del arte en este contexto, dada su gran carga simbólica y social.

El análisis de dos casos de estudio y algunos ejemplos desarrollados en el ámbito barcelonés y español nos permiten problematizar las siguientes cuestiones: ¿cuáles son las estrategias de trabajo de las denominadas prácticas artísticas al vincularse a procesos de recuperación de espacios de memoria?, ¿qué planteamientos teóricos desarrollan estas prácticas para establecer estrategias de transmisión en relación al debate controversial en la esfera pública, a los significados de la ciudad actual, a los nuevos usos o al imaginario colectivo?, ¿qué procesos y formas de coproducción promueven?

Palabras ClaVe: prácticas artísticas, arte público, espacios de memoria, espacios de represión, Barcelona. 
ABSTRACT: The main goal of this research is to analyze the exercise of artistic practice and its power in relation to the transmission of social demands in the urban transformation of places of memory, especially places of repression. Our interest lies in identifying the symbiotic relationships between contemporary art practices, social demands and memory spaces, particularly noting the potential of art in this context due to its great symbolic and social weight.

The analysis of two case studies and other examples developed in Barcelona and Spain allow us to problematize the following questions: What are the strategies artistic practices adopt when participating in processes to recover spaces of memory? What theoretical approaches do these practices suggest to establish transmission strategies in relation to the controversial debate in the public sphere, the meanings of today's city, and new uses or collective imaginary? Which processes and forms of coproduction do they promote?

KEYWORDs: artistic practices, public art, memory places, repression spaces, Barcelona.

RESUM: L'objecte d'aquest article és la reflexió al voltant de les pràctiques artístiques i el seu potencial en relació a la transmissió de les reivindicacions socials en processos de transformació urbana i recuperació de la memòria en espais de repressió. Espais que en nombroses ocasions es troben subjectes a transformacions urbanes i nous usos. Ens interessa identificar les relacions simbiòtiques entre pràctiques artístiques contemporànies, reivindicacions socials i espais de memòria, observant el particular potencial de l'art en aquest context, atesa la seua gran càrrega simbòlica i social.

L'anàlisi de dos casos d'estudi i alguns exemples desenvolupats en l'àmbit barceloní i espanyol ens permeten problematitzar les qüestions següents: quines són les estratègies de treball de les anomenades pràctiques artístiques en vincular-se a processos de recuperació d'espais de memòria?, quins plantejaments teòrics desenvolupen aquestes pràctiques per establir estratègies de transmissió en relació al debat controversial en l'esfera pública, als significats de la ciutat actual, als nous usos o a l'imaginari col-lectiu?, quins processos i formes de coproducció promouen? 
PARAULes CLAU: pràctiques artístiques, art públic, espais de memòria, espais de repressió, Barcelona.

\section{Heterotopías}

Con la lectura de la conferencia pronunciada por Michel Foucault en 1967 titulada «Des espaces autres» (y que Ángel Gabilondo traduce en 1999 como «Espacios diferentes»), entramos de lleno en la conceptualización de lo que el autor denomina heterotopías:

[...] lugares reales, lugares efectivos, lugares diseñados en la misma institución de la sociedad que son una especie de contraemplazamiento, una especie de utopías efectivamente realizadas en las que los emplazamientos reales, todos los demás emplazamientos reales que es posible encontrar en el interior de la cultura, están a la vez representados, impugnados e invertidos, son una especie de lugares que están fuera de todos los lugares, aunque sin embargo resulten efectivamente localizables. (Foucault, 1999, p. 435)

Se trata de una definición a la vez contradictoria y maravillosa a la que nos acercamos para conceptualizar el lugar de cruce en el que nos situamos para abordar el objeto de este artículo, cuyo interés se centra en las relaciones de las prácticas artísticas contemporáneas vinculadas a reivindicaciones ciudadanas para espacios públicos y equipamientos en relación a la recuperación y transmisión de su memoria.

Foucault entiende estas heterotopías como emplazamientos, en una concepción moderna (no medieval) del espacio. Lejos de difundirse por doquier en el sistema urbano, son en sí lugares de lo otro; de la desviación (cárceles, asilos, psiquiátricos...); del reflejo de la utopía (jardines, colonias...), de la yuxtaposición (teatros, cines...), de nuestra relación con el tiempo (cementerios, museos, archivos... pero también ferias y fiestas). Asimismo, expresa la necesaria condición de su limitación con el entorno, a menudo trascendida a través del control de su permeabilidad en forma física, simbólica y o ritual (hammams, iglesias, aeropuertos...). 
Una característica de estos lugares es su capacidad de transformación y adaptación:

Cada heterotopía, afirma el autor, tiene un funcionamiento preciso y determinado en el interior de la sociedad, y la misma heterotopía puede, según la sincronía de la cultura en la que se encuentra, tener un funcionamiento u otro. (Foucault, 1999, p. 436)

En esta condición de capacidad transformativa aparece el ejercicio de la práctica artística y su potencial en relación a la transmisión de las reivindicaciones sociales en procesos de regeneración urbana y recuperación de la memoria en el contexto de nuevos paradigmas de gobernanza. Prácticas interesadas en los últimos años por entornos de reivindicación concretos, en numerosas ocasiones vinculados a la recuperación de la memoria. Espacios de una gran potencia simbólica y cultural, que en ocasiones pueden asociarse a las características heterópicas que describiera Foucault.

En el siguiente artículo nos interesa identificar las relaciones simbióticas entre prácticas artísticas contemporáneas, reivindicaciones sociales y espacios de memoria, y observar el particular potencial del arte en este contexto. En este sentido destacamos algunos ejemplos en el ámbito español en relación a prácticas artísticas en espacios de represión, de los que nos interesa destacar las siguientes cuestiones: ¿cuáles son las estrategias de trabajo de las denominadas prácticas artísticas cuando se vinculan a procesos de recuperación de espacios de memoria?, ¿en función de qué planteamientos teóricos desarrollan estas prácticas sus estrategias de transmisión, en relación a los significados de nuestras ciudades, a los nuevos usos o al imaginario colectivo? ¿Qué procesos y formas de co-producción promueven?

\section{Prácticas artísticas y espacios de memoria}

Existen diversas confluencias de interpelación social entre el arte público, las prácticas artísticas y los procesos de memorialización. Asimismo, las reivindicaciones ciudadanas sitúan en su agenda política la recuperación de espacios para nuevos usos públicos, atendiendo, en nume- 
rosas ocasiones, a aspectos vinculados con la recuperación y la transmisión de la memoria.

El concepto de práctica artística tiene imbricaciones con el trabajo de teóricos como Henri Lefebvre y grupos coetáneos como la Internacional Situacionista. Para Lefebvre, la práctica social es un ejercicio político que:

[...] engloba producción y reproducción, [en] lugares específicos y conjuntos espaciales propios de cada formación social; [y] asegura la continuidad en el seno de una relativa cohesión. Por lo que concierne al espacio social y a la relación con el espacio de cada miembro de una sociedad determinada, esta cohesión implica a la vez un nivel de competencia y un grado específico de performance. (Lefebvre, 1974, p. 92)

Desde el ámbito artístico, el concepto de práctica se desarrolla con la cultura de la posmodernidad a partir de la desobjetualización del producto artístico y la adopción del entorno urbano como objeto de trabajo, entendido éste tanto desde su dimensión física (espacio público) como política (esfera pública); en una nueva consideración ética y estética del ejercicio de la creación. Se trata de un nuevo paradigma del objeto del arte, su producción y diseminación en el que se configura un nuevo sistema de relaciones entre productor y receptor (audiencia), con múltiples modos de interacción entre ambos.

Los emplazamientos y ámbitos de actuación de estas prácticas abarcan más de lo que Rosalind Krauss denominaba «lógica del monumento», produciéndose un abandono de la misma al introducir concepciones espaciales de la arquitectura y el paisaje para entender la...

[...] experiencia arquitectónica - las condiciones abstractas de apertura y cierre- en la realidad de un espacio dado", además de considerar una transformación con respecto al medio y su diversidad de expresiones, tanto que "la práctica no se define en relación con un medio dado -escultura- sino más bien en relación a las operaciones lógicas en una serie de términos culturales, para los cuales cualquier medio - fotografía, libros, líneas en las paredes, espejos o la misma escultura- pueden utilizarse. (Krauss, 1978) 
Suzanne Lacy (1995) y otros teóricos, interpelados por la nueva situación del arte a finales del siglo xx, se aproximan a algunas de sus definiciones desde múltiples perspectivas. (Butler, 2000; vVAA, 2001; Crespo, 2016).

For the past three or so decades visual artists of varying backgrounds and perspectives have been working in a manner that resembles political and social activity but is distinguished by its aesthetic sensibility. Dealing with some of the most profound issues of our time - toxic waste, race relations, homelessness, aging, gang warfare, and cultural identity - a group of visual artists has developed distinct models for an art whose public strategies of engagement are an important part of its aesthetic language. The source of these artworks' structure is not exclusively visual or political information, but rather an internal necessity perceived by the artist in collaboration with his or her audience.

We might describe this as «new genre public art», to distinguish it in both form and intention from what has been called «public art» — visual art uses both traditional and nontradictional media to communicate and interact with a broad and diversified audience about issues directly relevant to their lives - is based on engagement. (Lacy, 1995, p. 19)

Lacy contrapone en este texto de 1995, el conjunto de prácticas artísticas que denomina New Genre Public Art con el concepto de "public art», que en el contexto norteamericano se circunscribe al conjunto de objetos y proyectos aparecidos en el espacio público impulsados por los programas de las principales agencias estatales a partir de los años 60. Pero el concepto de arte público, desde una perspectiva histórica más amplia, puede acoger —en sus vínculos con el diseño urbano y las formas de producción urbana en un nuevo paradigma de gobernanza - algunas formas de estas prácticas:

Frente a la opinión generalizada de considerar el Arte Público como una especie de «aplicación» del ARTE en el espacio público, centrada en la relación entre la evolución de los lenguajes del arte y su incrustación en el suelo urbano, prefiero entender como arte público: «la práctica social cuyo objeto es el sentido del paisaje urbano mediante la activación de objetos/acciones de un marcado componente estético, siendo así que una parte de los elementos de mobiliario urbano encajarían en esta definición. Si el objeto del Arte Público es producir sentido para áreas territoriales, su objetivo es co-producir el sentido del lugar en consonancia con las prácticas de diseño urbano que conforman la morfología del espacio público. (Remesar, 2016a) 
Paralelamente, el arte público permanece en el espacio público en función de sus valores intrínsecos, ya sean de carácter arqueológico, como histórico, artístico, antropológico, etc., al tiempo que es un objeto de transmisión y permanencia de la memoria colectiva, pero esta misma cualidad de permanencia desaparece y deviene un arte efímero ya sea por su propia ejecución debido a los materiales con que se realiza, ya sea que su contundencia como relato histórico puede ser recriminada y rechazada en momentos de tensión política y social. (Grandas, Remesar, 2008)

En ellas se explicita una reflexión constante sobre lo público y sus límites, y emerge la necesidad de colaborar entre disciplinas y profesiones - pero también entre actores y agentes diversos-, en un marco de trabajo interdisciplinar que diluye los límites de la autoría artística (Remesar, Ricart, 2010; Brandão, 2011). Surge entonces una perspectiva diferente de actuación en el espacio público, dando paso a una serie de reflexiones que comienzan a debatir sobre el entorno y el contexto, y afectan por ende a las formas artísticas de la conmemoración.

La pertenencia a un entorno se desarrolla acorde a los límites espaciales y conformaciones urbanas, los comportamientos y prácticas sociales, así como a los estilos de vida y a la historia común (Brandão, 2011). La memoria constituye uno de los principales elementos constructores de la identidad urbana, resultando necesaria la existencia tanto del lugar como de la sedimentación temporal para que se produzca. La memoria nace de la subjetividad, y el punto de partida es la experiencia vivida o transmitida. La memoria es un acto colectivo, donde confluyen los principales trazos espaciales y temporales de los acontecimientos sociales.

La curiosidad por los lugares donde se cristaliza y se refugia la memoria está ligada a este momento particular de nuestra historia. Momento en el que la conciencia de la ruptura con el pasado se confunde con el sentimiento de una memoria desgarrada; pero en el que el desgarramiento despierta aún bastante memoria para que pueda plantearse el problema de su encarnación. El sentimiento de continuidad se vuelve residual a los lugares. Hay lugares de memoria porque no hay más medios de memoria. (Nora, 1984)

Nora apunta que la razón de ser de un lugar de memoria es luchar contra el olvido, detener el tiempo y fijar el estado de los acontecimientos para 
conservar el mayor número posible de sentidos en una pequeña porción de espacio, cuando, simultáneamente, los lugares de memoria no pueden evitar permanecer en un situación de metamorfosis y transformación, con un emanar constante de significaciones añadidas. Estela Schindel, en su trabajo sobre el lenguaje latinoamericano de la memoria, reflexiona sobre la adopción de los «"lugares de memoria" como espacio privilegiado de disputa por la construcción de memorias colectivas en las sociedades [...] afectadas por dictaduras o conflictos armados internos» (Schindel, 2009).

La relación entre el espacio y la memoria puede ser leída desde un enfoque disciplinario (memoria urbana, histórica, social), pero también existe una diferenciación de lecturas del espacio que influye en la percepción tanto del entorno global como de la memoria del lugar, y de la memoria transmitida en el espacio.

Si incluso los sobrevivientes de los campos que durante años guardaron silencio debido a esas atroces experiencias comienzan a dar testimonio en relatos y recuerdos que a su vez se ven alcanzados por la problemática de toda representación de la memoria, toda negativa a representar deviene en un estereotipo o en una apología estetizante o política. Lo que está en cuestión hoy en día es cómo resolver la transmisión inexorablemente mediática de un trauma de la humanidad a las generaciones nacidas después de las víctimas, de los victimarios y de los compañeros de ruta, a través de múltiples discursos artísticos, musicales, periodísticos, autobiográficos y científicos. Sólo la multiplicidad de discursos garantiza una esfera pública de la memoria, en la que, por cierto, no pueden tener el mismo valor todas las representaciones. Nunca existe una única forma verdadera del recuerdo; es probable que la problemática de la representación se resuelva en la comparación de discursos diferentes antes que en el debate académico sobre la forma correcta de la (no-) representación. (Huyssen, 2001, pp. 123-124)

Los episodios más traumáticos de la historia se gravan en la memoria de la manera más acentuada debido a la multiplicidad de sensibilidades que despiertan. La recuperación de esta memoria asociada al espacio público ha sido estudiada desde las dimensiones de la represión y el drama humano. La voluntad de recordar va unida en gran medida a la sonorización de las voces silenciadas por situaciones opresivas y la visibilidad de hechos eliminados de la escritura de la historia. Existe una vinculación entre la muestra, el reco- 
nocimiento y la asimilación social de los acontecimientos. Estos capítulos ponen de manifiesto intenciones políticas y relaciones de poder ocultas, lo que confiere complejidad al mantenimiento de evidencias o al descubrimiento de subjetividades incómodas políticamente. En este sentido, los espacios de represión son aquellos espacios cuya carga simbólica está vinculada a la opresión y masacre, principalmente política, en referencia a regímenes autoritarios. Cárceles, campos de concentración, campos de internamiento, campos de fusilamiento, fosas comunes, cementerios, centros de extorsión y tortura, refugios... Tratamos de entender la represión política a través de los soportes espaciales - técnicos y materiales - del horror, de la tortura y la supresión de derechos humanos vividos por la población.

Estos espacios no sólo forman parte de los espacios de memoria por albergar acontecimientos importantes, no sólo son parte de los lugares de memoria por su vinculación afectiva y social, sino que trascienden el espacio físico y de vivencias a través del aspecto de trauma humano, de muerte y tortura de masas, que no sólo trata las relaciones de poder, sino la supervivencia de grupos sociales en desacuerdo o desiguales al patrón hegemónico. Volvemos pues a un sentido heterotópico, en palabras de Foucault, del espacio.

Las reflexiones acerca de la memoria presentan un factor variable en función de la perspectiva que potencia su expresión, es decir, las relaciones de poder que muestra, pues mientras la atención histórica recaía en los héroes, no lo hacía en las víctimas o en el testigo y viceversa. Y esto ha influido cuantiosamente en los tipos de discurso y formalizaciones que han asumido los canales de transmisión (el arte público pero también la arquitectura, el diseño...), dejando un legado de cambios de paradigma y enfoques a los que nos enfrentamos hoy.

La memoria, como hecho colectivo, «proyecta «un sentido difuso pero sin embargo de gran alcance que impregna muchas escenas urbanas y puede desempeñar un papel importante en la animación de los movimientos políticos y sociales» (Harvey, 2003. En, Remesar y Ricart, 2013b). Ese espacio privilegiado de disputa, recalca el aspecto relacional y temporal de la memoria sobre el que David Harvey (2003) se sostenía, y confiere un papel 
definitorio a los lenguajes de transmisión como sub-marcos de la memoria (Halbwachs, 1925) y el mensaje que emiten.

Las políticas públicas que inciden en la conformación de la imagen de la ciudad adoptan estrategias que ahondan no sólo en la producción de objetos sino en preservar aquellos símbolos del territorio que en muchos casos pueden identificarse con edificios históricos o infraestructuras relevantes de la red urbana. Vinculadas a la protección de estas construcciones como patrimonio histórico se encuentran aquellas intervenciones que dotan de nuevos usos y funciones a edificaciones significativas, sirviendo de albergue a organismos e instituciones públicas, conformando nuevos equipamientos educativos, hospitalarios, culturales...

Las cárceles - como espacios de represión que han presenciado capítulos trascendentes en la memoria de una ciudadanía que ha pasado por regímenes autoritarios y etapas de represión política-, vinculadas a la memoria histórica y urbana de las ciudades, albergan un doble valor: primero patrimonial, en relación a la historia del lugar; por otro, infraestructural, como equipamiento susceptibles de ser transformado para nuevos usos. Se trata por tanto de espacios de memoria singulares, que han sido objeto de complejos debates públicos en numerosos países. Estas heterotopías, en palabras de Foucault, suelen contar con amplias instalaciones en puntos estratégicos de la trama urbana tras el crecimiento de las ciudades. El ámbito cultural incide a varios niveles sobre la transformación de estos espacios: primero, preservando parte de su estructura física mediante mecanismos de restauración y conservación; segundo, aportando programas de reconversión en equipamientos culturales (museísticos o no, que intercedan como archivo congelado del tiempo, que apuesten por la exposición y creación contemporáneas, etc.); tercero, incidiendo mediante intervenciones artísticas sobre la carga simbólica que contiene el conjunto, a través de manifestaciones próximas al arte público, la monumentalización o, en los procesos de transformación hacia nuevos usos, en forma de prácticas artísticas que contribuyan a la reivindicación, recuperación y transmisión de la memoria. 


\section{Transmisión}

La proximidad producida a mediados del siglo pasado entre la forma institucionalizada de la escultura - el monumento- y el arte moderno ha permitido transferir herramientas para la transmisión simbólica con las que poder incidir en la expresión de la memoria en la ciudad, abriendo un campo de comunicación entre los lenguajes actuales tanto urbanos como de interacción pública. La memoria precisa mantener un contacto contemporáneo con la vida en las ciudades, y para ello, las materializaciones que adopte deben participar en la transformación del espacio público y de la sociedad.

En la actualidad, surgen nuevas formas de disposición del arte como canal de transmisión de la memoria, e incluso nuevas conexiones entre disciplinas (arquitectura, sociología, arte, historia). Asimismo la vinculación entre agentes administrativos, profesionales, académicos, asociaciones, movimientos sociales y ciudadanos, está más presente y plantea su participación desde una posición más próxima.

Mientras los recursos tradicionales de las artes visuales siguen teniendo cabida, otras presentaciones no tradicionales exponen su habilidad para la transmisión. Es así que mientras el aspecto temporal empieza a resaltar su presencia en la dinamización del espacio público, las intervenciones efímeras, la performance, las proyecciones audiovisuales y las prácticas de acción, recalcan en gran medida la atención sobre el proceso, vinculado de alguna manera con aquellas manifestaciones de la cultura más próximas a la celebración, el evento, el ritual. Como las llevadas a cabo en el centro de creación contemporánea en el que se ha ido transformando la antigua prisión provincial de Segovia; el proyecto de rehabilitación conserva la distribución y estructura de la antigua prisión, pero otorgando un nuevo sentido a los espacios para desarrollar la metáfora que este proyecto quiere construir, acercar la creatividad para acercar la libertad. Por otro lado, la plataforma ciudadana Futur Monument a la Presó de Dones de Les Corts confiere un papel esencial a la dinamización del espacio de memoria como herramienta para la visibilidad, siendo la celebración del lugar y la práctica artística efímera (o temporal, provisional) elementos clave para dar continuidad a la consecución de objetivos propuestos de monumentalización. 
Asimismo, las movilizaciones sociales en un contexto político internacional donde se aboga por la democracia desde mediados del siglo pasado, inciden directamente en el reclamo de la inclusión de la ciudadanía en las intervenciones realizadas en lo público, y no sólo para sino con y en él.

Las tendencias de las manifestaciones artísticas de los últimos años provienen de estas formas de incursión en el entorno urbano, y permanecen explorando las vías más cercanas a la participación, interacción, interpelación e intervención, generando prácticas con un sentido de proceso abierto y vivo.

Henri Lefebvre (1974), en La producción del espacio expone una consideración acerca de las interferencias en el espacio social, es decir, entrecruzamientos de la constitución del espacio y las representaciones simbólicas del mismo, que generan tres dimensiones superpuestas (la práctica espacial, las representaciones del espacio y los espacios de representación) a las que se asocian tres concepciones de espacio: el espacio percibido — una interacción dialéctica con los agentes -; el espacio concebido - con un sistema de signos en los que traducir la información-; y el espacio vivido — con imágenes y símbolos que recorren el espacio físico.

Podemos dar por descontado que las representaciones del espacio poseen un alcance práctico, que se engastan y modifican las texturas espaciales, impregnadas de conocimientos e ideologías eficaces. Las representaciones del espacio tendrían de ese modo un impacto considerable y una influencia específica en la producción del espacio. ¿Pero cómo? Mediante la construcción, es decir, por la arquitectura, concebida no como la edificación de un «inmueble» aislado (palacio o monumento) sino en calidad de un proyecto insertado en un contexto espacial y en una textura, lo que exige «representaciones» que no se pierdan en el simbolismo o en el imaginario. En cambio, los espacios de representación no serían productivos, sino tan sólo obras simbólicas. Éstas son a menudo únicas; en ocasiones determinan una dirección estética y, después de cierto tiempo, se consumen tras haber suscitado una serie de expresiones e incursiones en el imaginario. (Lefebvre, 1974: 100)

Pero ¿de qué mecanismos o estrategias se sirven estos lenguajes?

El artista Perejaume (2010) en su escrito Paraules locals nos propone una reflexión acerca de la transmisión de la cultura y asentamiento de la información local entre generaciones y sobre los lugares. El autor presta especial 
atención a tres formas de transmisión que han funcionado desde distintos ámbitos: la agricultura, la academia y la industria.

En el fons una cultura i altra (la cultura académica y la cultura agraria) són irreconcialables: un Pagés us diría «només es conserva el que es repeteix». No hi ha, per a ell, altre suport que la transmissió viva, generació rere generació, llavor rere llavor. Un acadèmic, en canvi, creu que allò que es conserva és allò que es fixa. I d'aquí ve la dèria pels suports duradors - els marbres, els bronzes..., però també el formigó, l'acer inoxidable...-, així com la dèria per les diverses formes d'arxiu, historiogràfiques, museogràfiques, alfabètiques, etc. Penseu en el triomf de la pintura o de la imprenta como una visió salvada, fixada: que no es dissol. A tot això encara hi ha un tercer parer molt genuí del període industrial, més específicament pop podríem dir-ne, que ve a dir que només es conserva alló que es multiplica: feu milers i milers d'exemplars d'una mateixa cosa, que per molts que se'n perdin, un o altre en quedarà. (Perejaume, 2015, p. 21)

La repetición, la fijación y la multiplicación (o reproducción) aparecen aquí como métodos para asimilar la cultura, o, si lo extrapolamos, como estrategias de transmisión aplicables a los lenguajes de transferencia de la memoria. En el arte, arquitectura y diseño encontramos la fijación en los soportes duraderos - como apunta Perejaume - en los mármoles, bronces, hormigón, acero inoxidable, de la escultura pública, pero también la repetición y la multiplicación se manifiestan como formas recurrentes en las prácticas que tratan la memoria. La primera la encontramos por ejemplo en las celebraciones y actos conmemorativos recurrentes así como en el uso de símbolos para la dignificación; y la segunda la encontramos por ejemplo en monumentos seriados y también en intervenciones que reproducen el mismo elemento a modo de reiteración.

El concepto que Lefebvre utilizaba para referirse al lenguaje en los espacios de representación, al que denomina código, podemos vincularlo al de transmisión del que se sirven autores como Régis Debray - desde un enfoque mediológico - o Perejaume - desde un enfoque artístico- para definir la transferencia de la memoria, pues la transferencia de información precisa unos signos que emisor y receptor puedan percibir. Régis Debray (2001) señala que: «Para abordar el continente del "transmitir", que no es visible al ojo y que, como todos los conceptos operativos, no 
se puede recibir como una experiencia inmediata, hay que trascender el horizonte del "comunicar"» (Debray, 2001, p. 15), indicando que bajo el término comunicación está la circulación del mensaje en un tiempo concreto; sin embargo, en la transmisión reside aquello relacionado a la dinámica de la memoria colectiva a través de tecnologías que permitan el acceso al conocimiento y a la concepción del mundo que deriva de ello. Denomina «tecnologías de la memoria» a las influencias de los avances tecnológicos en la transferencia del conocimiento, exponiendo «medioesferas» que condicionan la mentalidad comunicativa colectiva: mnemoesfera primitiva (artes no escritas), logoesfera (invención de la escritura), grafoesfera (invención de la imprenta), y videoesfera e hiperesfera (imagen-sonido-herramientas digitales) (Debray, 2001, pp. 66-77). Podría señalarse una categoría más que dista del mundo tecnológico, pero podemos contemplarla como medioesfera de la comunicación que produce la transferencia de conocimiento vivencial. Podríamos vincularla a la mnemoesfera primitiva — pues nos referimos a artes no escritas-, aquélla que engloba la interacción corporal de los actores a través de eventos, celebraciones y rituales, por medio de la expresión, interacción corporal y/o la performance como herramientas. Es ejemplo de ello la intervención «Memorial Movement» llevada a cabo en 2015 en distintos espacios de represión de Barcelona, cuestionando la necesidad de instalaciones permanentes conmemorativas en las sociedades contemporáneas.

Estas tecnologías son también mecanismos vigentes de transmisión, que no han de despistarse de la carga simbólica del lugar de memoria, como quizás haya pasado en ciertos momentos del desarrollo del Parque Cultural de Valparaíso, al desatender ciertos valores de la ex cárcel en detrimento de la esfera del Arte, aunque el equipamiento ofrezca programas e instalaciones de gran relevancia.

Así, la visión de la vida de la ciudad y en la ciudad adopta un carácter multidimensional debido a la yuxtaposición de distintos canales de transmisión de la memoria en el espacio urbano, que ayudan a crear nuevos lenguajes y actualizar los existentes. 


\section{Reivindicación. Recuperación}

La reivindicación, la recuperación y la transmisión son acciones permanentes en los procesos vinculados a las prácticas artísticas en espacios de memoria. Algunos ejemplos en esta dirección son los procesos y prácticas desarrollados en espacios de represión como son la reconversión de la cárcel de Valparaíso (Chile), los proyectos planteados para la cárcel de Carabanchel (Madrid), la rehabilitación de la cárcel provincial de mujeres de Segovia o los programas de actividades y nuevos usos culturales de la cárcel de A Coruña. Otros en los que hemos colaborado y que presentamos sucintamente son el proceso que promueve la plataforma Futur Monument a la Presó de Dones de Les Corts y el proceso iniciado por la plataforma Fem Nostre l'Espai de la Model, ambos en Barcelona. Las intervenciones realizadas o propuestas planteadas tienen en común la orientación hacia usos culturales que se les ha conferido; sin embargo, presentan importantes cuestiones acerca de los programas que redactan (pedagógicos, museísticos, artísticos...), los actores que los potencian (de iniciativa pública, privada, desde la ciudadanía...) y los lenguajes que utilizan para preservar y transmitir la memoria que subyace al espacio (conservación del patrimonio, archivo, expresión contemporánea, diseño urbano conmemorativo...).

The process of identity construction is not the result of only a piece of 'hardware', but involves an agreement on objectives among actors, a negotiating and communicative dynamics in the management of a 'software' that, in itself, is the identity creator and facilitator of its representation in public space. A strategy of building and assess identity through public space must also include hardware, software activities through proactive management and involving actors in the diagnosis, in the preparation of programs mobilizing for change and activities of management and post-occupancy evaluation (Brandão, 2011)

Debemos plantearnos las principales estrategias de estas prácticas artísticas visibilizadoras de las memorias de la represión; con algunas restricciones, ya apuntadas por Pedro Brandão en 2015 y recogidas por Antoni Remesar en 2016:

1. We cannot reconstruct the past in the present.

2. The temporality is not a gradual transition from one to another. 
3. The past and present are not distinguished by before and after.

4. The subject of memory are not facts, but their reconstruction. (Remesar, 2016c)

A las que añadimos:

5. La recuperación de la memoria no debería diluir el papel innovador del arte en relación a la capacidad para dinamizar socialmente y resignificar los lugares.

6. Los espacios de memoria deberían seguir atendiendo a su especificidad como espacios públicos y reflexionar en torno a su encaje singular con el resto de la red de espacios públicos de la ciudad.

La cárcel Modelo de Barcelona abre sus puertas en 1904 en el límite del entonces creciente ensanche de Barcelona, y lo hace impulsando un nuevo sistema penitenciario. La historia de la Modelo es, en su extremo, la historia del siglo xx. Los presos políticos han convivido con los comunes hasta la transición, cuando ya en democracia los últimos represaliados son por fin amnistiados. Pocos años después llegarán los estragos de la heroína (Fontova, 2010).

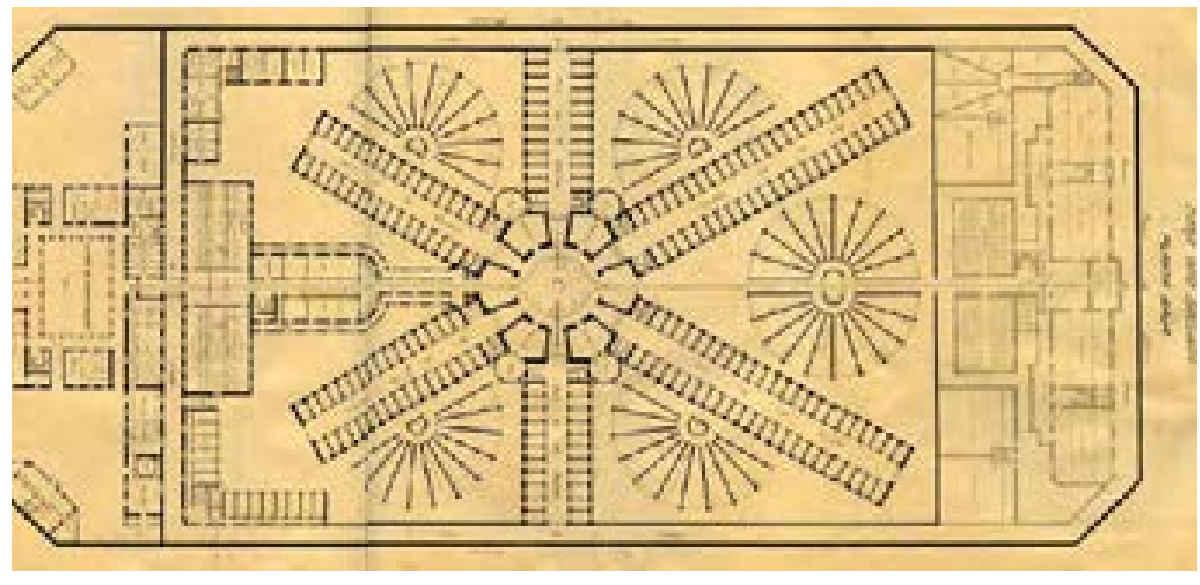

Figura 1. Plano de la Modelo de Barcelona, realizado por los arquitectos Josep Domènech i Estapà y Salvador Viñals. Fuente: Archivo Ateneu Enciclopèdic Popular. 
Tras la falta de actuaciones por parte de las administraciones para el reacondicionamiento de este espacio, en Mayo de 2016 se crea la plataforma Fem Nostre 1'Espai de la Model. ${ }^{1}$ En ella se integran ciudadanos, asociaciones, entidades y colectivos de dentro y fuera del distrito. Sus objetivos se centran en reivindicar: el cumplimiento de los plazos comprometidos por las administraciones; la consideración de usos exclusivos para la ciudadanía en forma de zonas verdes, equipamientos públicos y espacio de memoria - excluyendo por tanto los $14026 \mathrm{~m}^{2}$ destinados a uso terciario y por tanto a oficinas y hoteles previstos en la modificación del PGM; y el desarrollo de un proceso participativo en el que se reabran los debates en torno a todos y cada uno de los aspectos de la futura Modelo.

Desde el inicio, la plataforma tiene la voluntad de atender las diversas sinergias que conviven en el territorio y el tejido social. Por un lado, las reivindicaciones históricas de falta de equipamientos públicos lideradas por la Asociación de Vecinos y otras entidades; por otro, las demandas de verde urbano intensificadas en los distintos debates ciudadanos en los últimos años; y finalmente la dimensión de memoria histórica de la cárcel. Tres ejes de trabajo son el motor de un proceso participativo que reivindica su desarrollo a partir del uso del propio lugar como espacio de significación y altavoz de comunicación.

La Modelo sigue en el mismo lugar, aunque muy deteriorada. Esta situación ha sido denunciada por vecinos y asociaciones desde el inicio de la democracia; y las respuestas dadas por las administraciones (Generalitat de Catalunya y Ayuntamiento de Barcelona) han sido las de suscribir planes de transformación que no se han llegado a materializar. A inicios del año 2017 un convenio firmado entre el gobierno local y el autonómico abre lo que parece ser el inicio del proceso de transformación definitiva de la cárcel.

Desde el principio la recuperación de la memoria a través de la exposición pública de algunas obras del artista Helios Gómez (1905-1956) — preso ocho años en la Modelo durante la dictadura — es el catalizador para situar el

1. «Hagamos nuestro el espacio de la Modelo». 
debate de nuevo en el espacio y la esfera pública. Tras la denegación del permiso por parte de Instituciones Penitenciarias (Generalitat de Catalunya) en relación a la intervención mural propuesta (fig. 2) —aludiendo a un problema de seguridad vinculado a la imagen distorsionada que las imágenes de Helios Gómez pueden dar de una cárcel moderna en activo-, decidimos reformular el proyecto de intervención, sumando a sus contenidos los otros dos ejes reivindicativos de la plataforma.

Esta segunda propuesta (fig. 3) es en parte aceptada, en parte censurada. Esta respuesta dicotómica da pie a tres líneas de trabajo: primera, significar el espacio público desde el arte y la reivindicación a través de la intervención mural y la información pública del proceso; segunda, denunciar el ejercicio de censura; tercera, organizar actividades lúdicas y reivindicativas en el espacio para llevar a cabo un ejercicio real de transmisión y feedback de las reivindicaciones ciudadanas.

El proceso sigue en marcha habiendo logrado: uno, convertir un grupo heterogéneo de asociaciones y colectivos civiles en un interlocutor en el proceso de transformación; y dos, semantizar un espacio público vinculado a la Modelo mediante una intervención artística compuesta de un mural (a medias censurado) y un tótem informativo, claves para la interlocución (fig. 4 y 5).

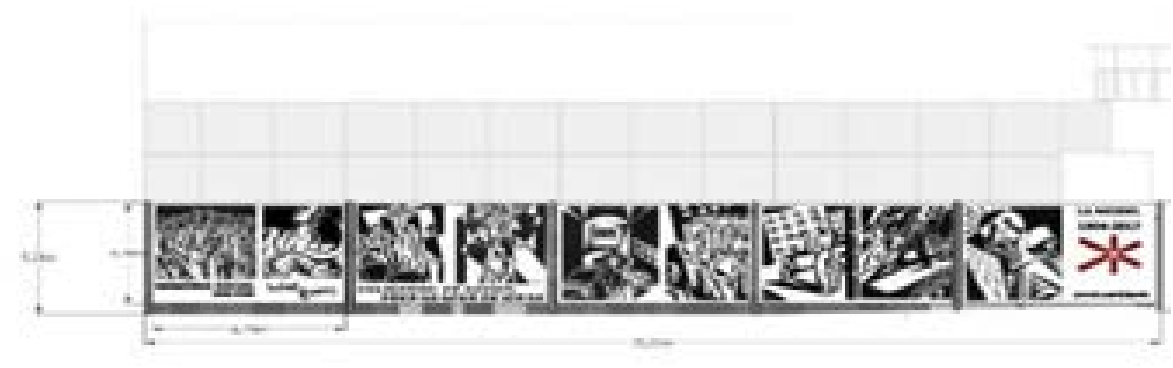

Figura 2. Proyecto de intervención mural, versión 2 (Núria Ricart, EUROM-UB, Asociación Helios Gómez, AVVEe). Reproducciones de obras del artista Helios Gómez (1905-1956). Permiso denegado por parte de Instituciones Penitenciarias (Generalitat de Catalunya), Noviembre de 2015. 


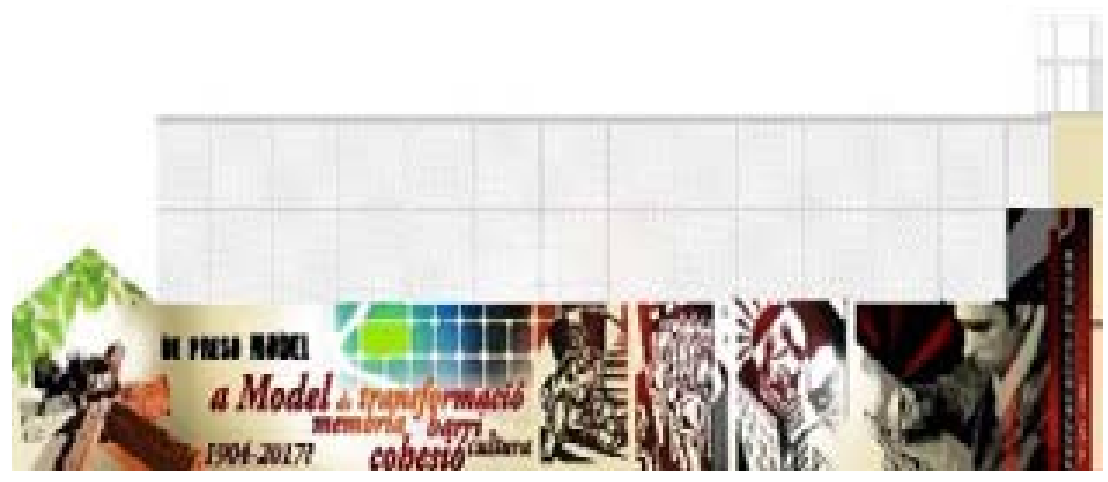

Figura 3. Proyecto de intervención mural (Plataforma Fem Nostre l'Espai de la Model, Roc Blackbloc). Reproducciones de obras del artista Helios Gómez (1905-1956) y reivindicaciones genéricas sobre la futura transformación. Permiso concedido a la parte textual del grafiti, siendo censurada la parte donde se prevé reproducir obra del artista Helios Gómez. Mayo de 2016.

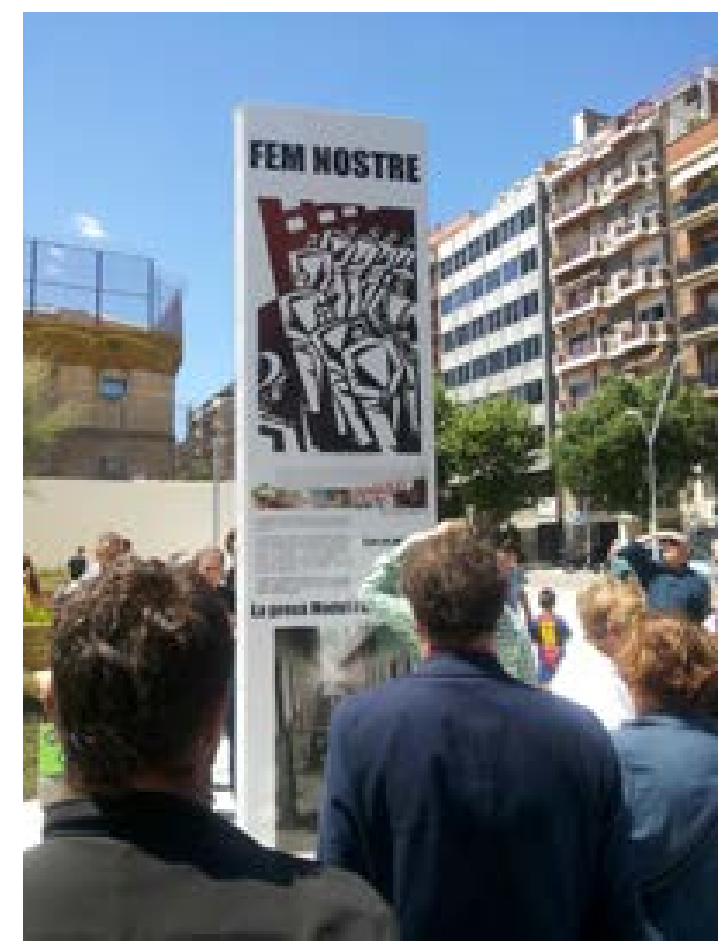

Figura 4. Tótem informativo sobre el proceso de transformación de la cárcel Modelo en base a tres ejes reivindicativos: memoria, equipamientos y verde urbano. Calles Rosselló/Entença (Modelo) (Fem nostre l'espai de la Model, Núria Ricart). Mayo 2016. 


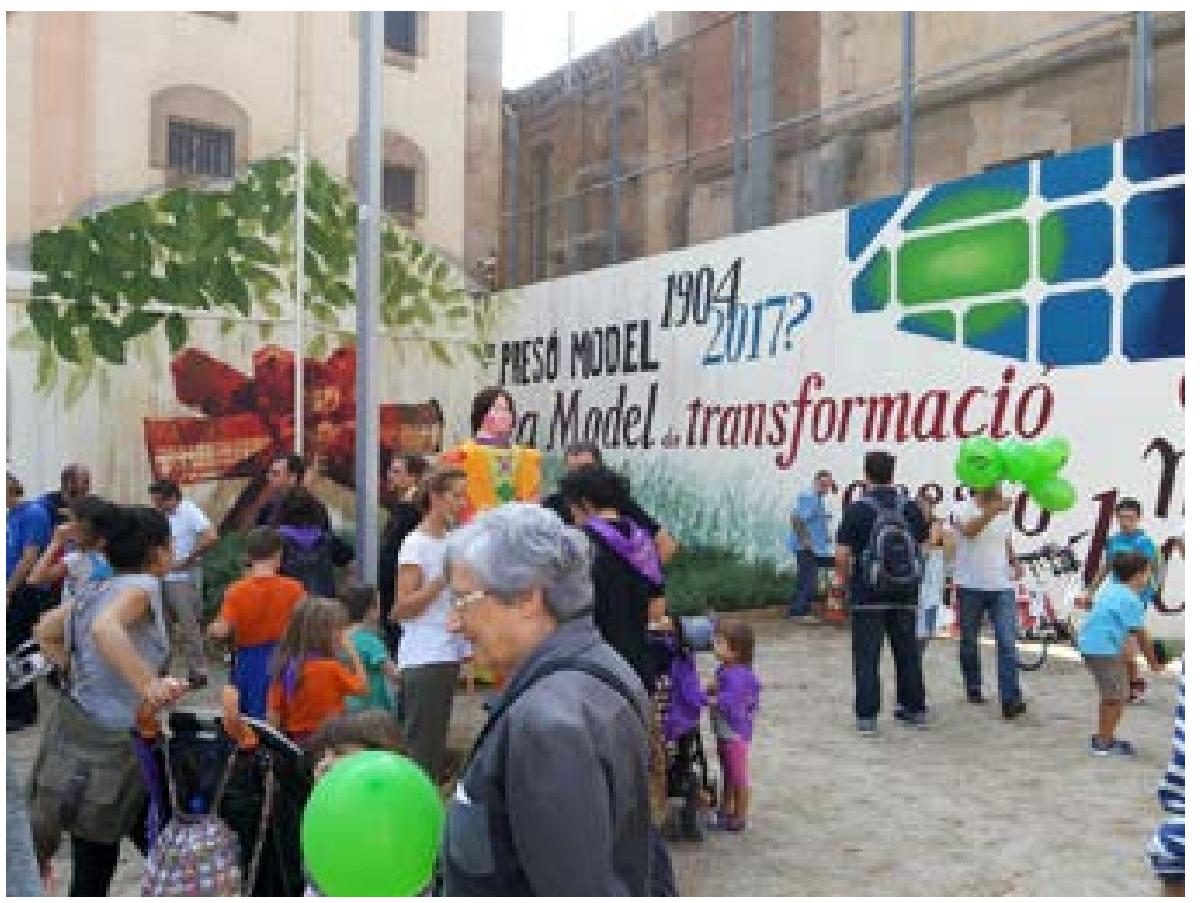

Figura 5. Fiesta reivindicativa, 2 de Octubre de 2016.

El otro espacio de represión que queremos señalar es la cárcel de mujeres de Les Corts, habilitada como prisión bajo el nombre de Correccional General de Mujeres con el gobierno de la Generalitat Republicana, y denominada durante la dictadura franquista como Prisión Provincial de Mujeres de Barcelona (1939-1955), tras albergar a presas políticas tanto de ideología derechista como anarquistas y militantes del Partido Obrero de Unificación Marxista (POUM) durante la Guerra Civil (Ricart; Guixé, 2015).

Sería en 1955 cuando se produciría la clausura de la prisión, al traspasar el grupo de presas a la cárcel Modelo de Barcelona, y ver una completa transformación de su perímetro y su final derribo. Se produce una modificación en la trama urbana con el levantamiento de edificios en la década de los 70, y con el asentamiento de dos ejes viales que atraviesan el solar, emplazándose posteriormente un gran bloque de uso comercial. «El cambio de uso y la consolidación del sector como centro administrativo y comercial al noreste de la ciudad, así como su proximidad a la zona universitaria, hace de esta área un núcleo de actividad ajeno a los hechos precedentes» (Remesar; Ricart. 2013a). La memoria del lugar de represión de género cae en el más absoluto olvido colectivo. 


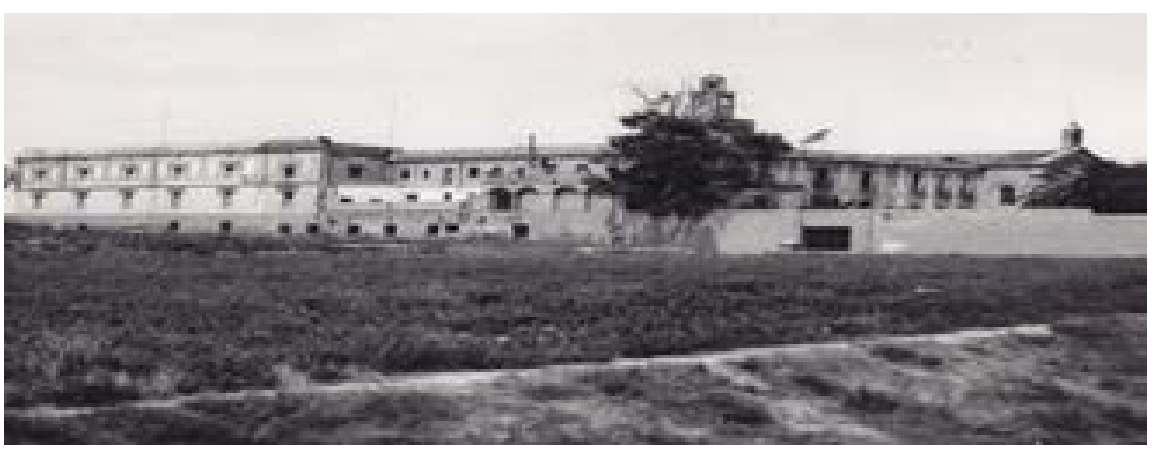

Figura 6. Vista de la antigua cárcel de mujeres de Les Corts tomada desde la actual avenida Carlos III. Fuente: Arxiu Municipal del Districte de Les Corts.
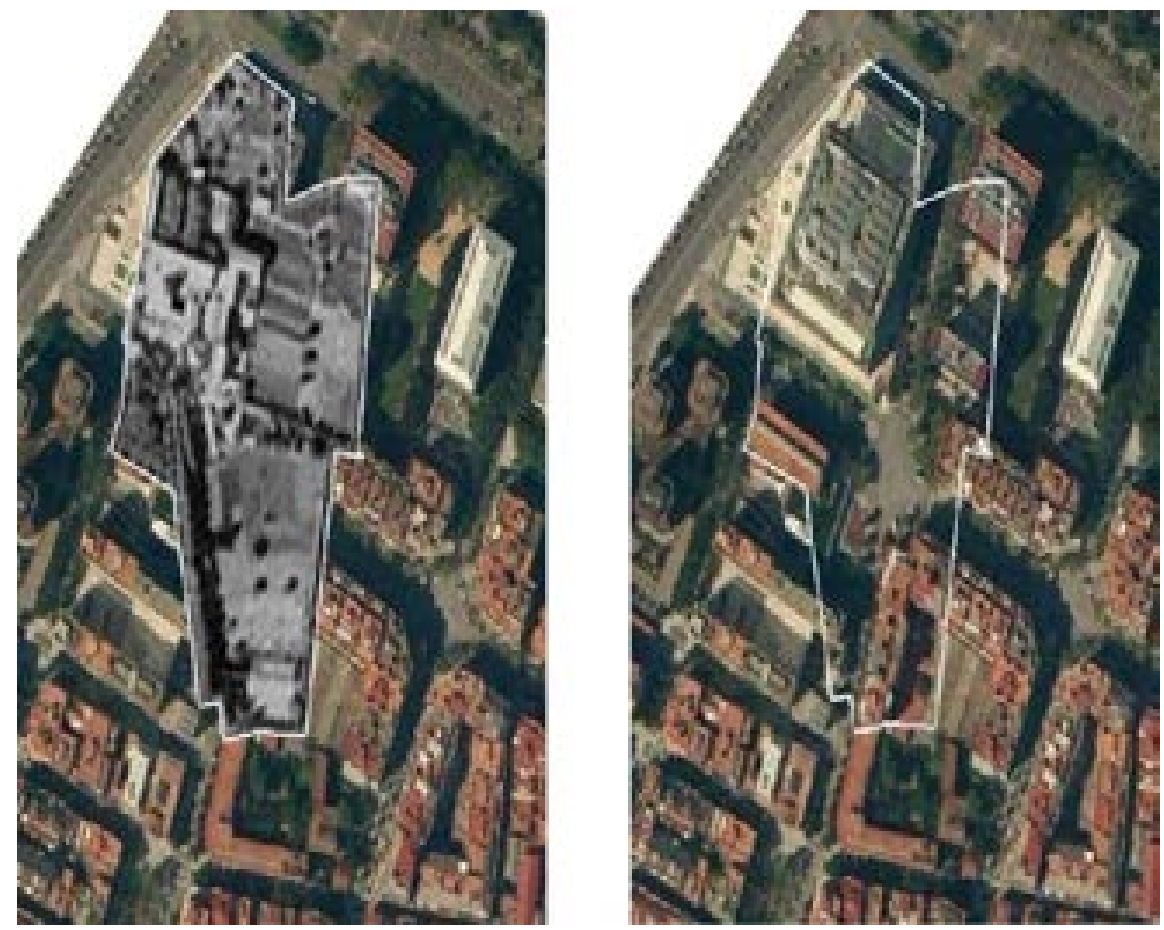

Figura 7. Perímetro de la cárcel sobre la trama urbana actual.

En el año 2010, se produce la iniciativa de señalizar la prisión mediante una placa conmemorativa colocada en un muro lateral de los almacenes comerciales; altamente criticada por su ineficacia. Comienza así un proceso de debate sobre la conmemoración en el espacio público al que se han ido sumando distin- 
tos actores y agentes urbanos. Desde 2013, tiene como objetivo la construcción de un monumento dedicado a las presas de la cárcel de Les Corts, que resulta en mesas redondas, mesas de trabajo, exposiciones, rutas y publicaciones, que más tarde ha dado lugar a una intervención artístico-informativa en el lugar, y que sigue en pie con un proyecto de materialización.

La iniciativa de recuperación de esta memoria surge de la sociedad civil — «familiars d'expresses, entitats $i$ associacions de dins i fora del districte com les Dones del 36, grups de recerca de l'àmbit acadèmic..., ciutadans $i$ ciutadanes»-, comienzan a tejer un proceso de recuperación y transmisión de una memoria silenciada a través de la organización de exposiciones, seminarios, obras de teatro, páginas web: presodelescorts.org...

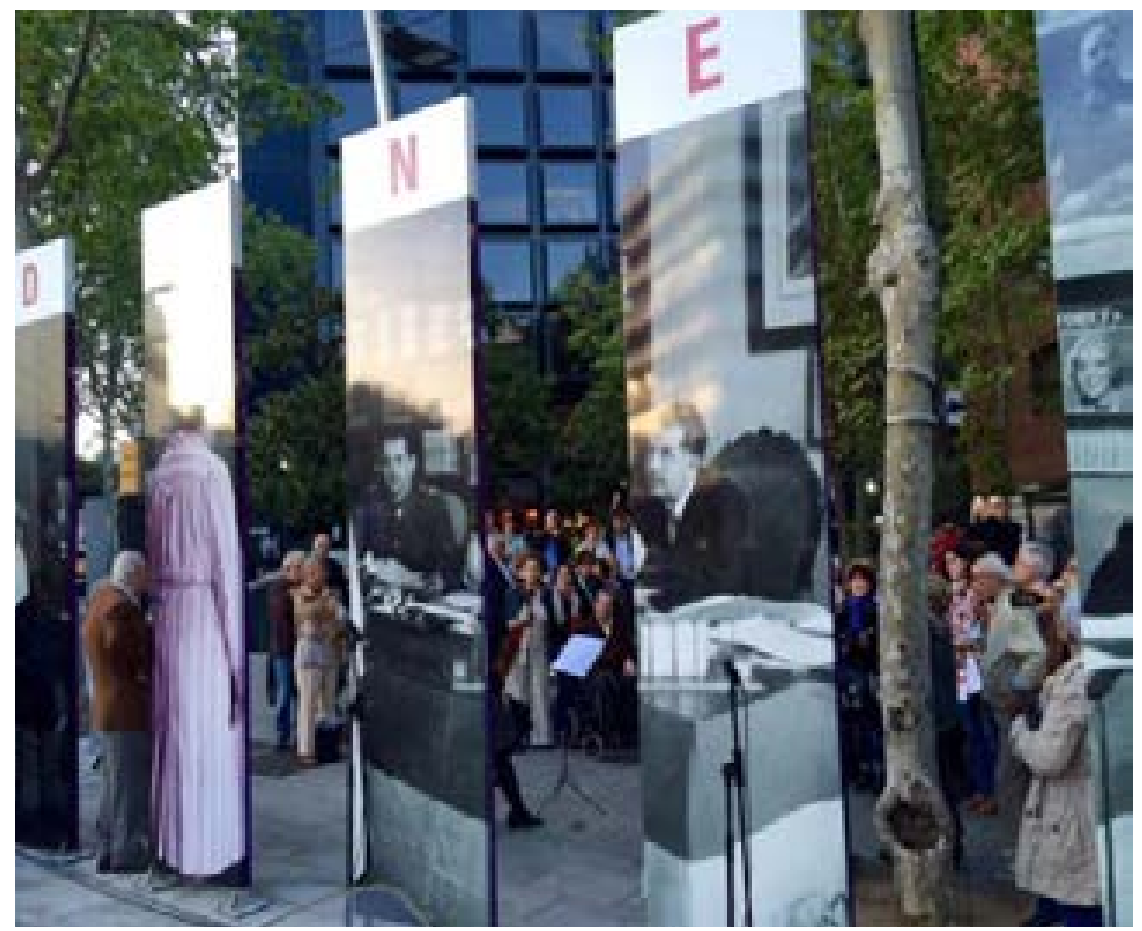

Figura 8. 14 de Abril de 2015. Conmemoración en el Espacio de Memoria Provisional Dones/Presó. 
En 2014, el proceso logra definir un espacio de memoria provisional en el chaflán noroeste de la intersección de las calles Europa y Joan Güell. Se trata del espacio conocido como: Dones/Presó. ${ }^{2}$ Este espacio de memoria, a medio camino entre la señalización informativa y la escultura, se fundamenta en cinco paneles de tres metros y medio de altura. «Dos són els elements quedeterminen la seva situació, escala i formalització»: la capacidad expresiva de la imagen y la capacidad de exposición abierta a las transformaciones del proceso; dado que una de las caras de los paneles es estable; su anverso, en cambio, se actualiza en relación a la evolución del proceso.

Este proceso es en sí el propio objeto de trabajo de la práctica artística en relación a la recuperación y transmisión de la memoria. Pero su rumbo sigue fijo en su objetivo último, buscando un nivel de permanencia que estos monolitos todavía no han alcanzado, un nivel de monumentalización del espacio público a través de la fijación de unos recursos materiales y formales. $\mathrm{La}$ construcción de un futuro monumento entendido como un espacio de conmemoración y transmisión social de la memoria.

\section{Práctica como proceso}

Los procesos de participación vinculados a la recuperación de la memoria inciden directamente en el conocimiento público de la experiencia vivida por parte de la ciudadanía en general, víctimas, testigos, generaciones posteriores y grupos implicados políticamente. Experiencia subjetiva en oposición a una narración objetiva, hegemónica y silenciadora de realidades con trascendencia en la composición de la sociedad. El archivo de la memoria recoge testimonios, documentos, objetos, fotografías, grabaciones, huellas, etc., que conducen a la reconstrucción de hechos sumergidos en la profundidad de la historiografía, pudiendo alcanzar durante el trayecto, distintas líneas de memoria que pueden superponerse, desde perspectivas colectivas, individuales, políticas, sociales, urbanas, cívicas, y — pese a la contradicción que pueda suponer- históricas.

2. «Mujeres/Cárcel». 
Las prácticas artísticas se imbrican en estos procesos, potenciando e incluso catalizando los consensos y disensos en los debates de los agentes urbanos participantes; a través de talleres, debates, eventos o productos que trasciendan el límite territorial y emitan transferencias en la esfera pública, despertando puntos de conexión entre diferentes ámbitos de la vida urbana.

Es ejemplo de ello el trabajo sostenido por la plataforma Proxecto Cárcere de A Coruña, para la recuperación del espacio de la cárcel de la Torre, antigua prisión provincial, con el que se realiza una demanda de uso y rehabilitación ante una situación de abandono y deterioro. Surge una concepción de demanda social desde la ciudadanía y colectivos expertos, para participar de las instalaciones con fines sociales, culturales y educativos, preservando la estructura y confiriendo valor a la memoria allí transferida. El debate abierto ha ido generando una movilización a nivel administrativo, social y artístico, dando lugar a múltiples reuniones a nivel institucional y con grupos sociales interesados en configurar la reconstrucción de esta memoria histórica y en obtener un lugar de uso público. Es todavía un proceso abierto desde el año 2010, que continúa presente.

El valor del proceso reside también en su dimensión temporal que propicia la gestación transdisciplinar del propósito con pequeñas actuaciones prácticas, sostenidas durante períodos prolongados para desarrollar el proyecto sin un cierre hermético, sino con el acabado de ciertas etapas. Y es este ritmo sincopado el que permite el desarrollo de una cadena de actuaciones en las que se persigue la retroalimentación social y la reconfiguración de la imagen de la ciudad desde una dinámica bottom-up.

El proceso permite el desarrollo de sub-proyectos que permitan prever soluciones a necesidades específicas evaluadas sin apriorismos.

\section{La memoria desde el presente}

El espacio público se halla en constante transformación; sin embargo, esta mutabilidad ha de afrontar un debate que sopese las fronteras del debate entre sostenibilidad y crecimiento de los proyectos urbanos. Una necesidad que ha de aprender del pasado pero sin estancarse en él, entonces los procesos urba- 
nos hallan ahí un lugar importante en la actualización constante de los requerimientos del ambiente y los posicionamientos a adoptar ante el desarrollo de propuestas. Existe una línea de memoria en constante construcción, sucesos paralelos a temáticas que ya se han dado en la historia (como actualmente sucede con el exilio y los grupos de refugiados), un contexto presente, con condicionamientos políticos, sociales y económicos, presentes, que precisan, incluso, ser entendidos como una memoria presente que está en efervescencia, y requiere simultáneamente su lugar de memoria.

Para este propósito, cabe entender aquellas prácticas que por un lado recuperan un lugar de memoria (o señalan un espacio de memoria sobre el que proyectar un recuerdo) ejerciendo una función conmemorativa, y por otro lado entienden las necesidades y nuevos usos que asume el entorno con el tiempo, respondiendo con un ejercicio de integración de la vida urbana actual, con el lugar simbólico y la memoria latentes y sus vínculos con la contemporaneidad.

El complejo de la cárcel de Carabanchel, Madrid, se cierra en 1998 y después de un tiempo se da paso a su abandono y degradación. Los años que la prisión permaneció inactiva, los vecinos del barrio solicitaron reiteradamente que el espacio se transformase en hospital y se dotase de otros equipamientos de carácter social, de gran necesidad, así como conservar por lo menos la cúpula como lugar de memoria. Sin embargo, tras el derribo llevado a cabo en 2008 por orden del Ministerio del Interior, y tras múltiples protestas y propuestas de rehabilitación por parte de diversos agentes urbanos, el Colegio de Arquitectos de Madrid mismo, el solar de 200000 metros cuadrados permanece vacío. El único edificio en pie es el hospital penitenciario, ahora reconvertido en nuevo espacio de represión, un Centro de Internamiento de Extranjeros. A pesar de esto, las propuestas continúan aparte del plan urbanístico que prometía equipamientos necesarios, orientándose bien desde prácticas de arte urbano en el perímetro de las inmediaciones, bien desde el planteamiento de cerrar el CIE y transformarlo en Centro para la Paz y la Memoria. Plataformas ciudadanas continúan dentro del proceso, como Salvemos Carabanchel. 


\section{Conclusiones}

En el siglo XXI se enmarcan, en el contexto español (como también en diversos puntos del panorama internacional con previas situaciones políticas agresivas como Argentina, Chile o México cobraban fuerza las iniciativas visibilizadoras de las voces clandestinas), las décadas de más atención sobre la recuperación de la memoria histórica (2000-2010), cada vez con más distancia del término de unas condiciones políticas de silencio obligado para poder volver sobre él y visibilizar verdades ocultas.

Es también el inicio de un siglo en el que el arte atraviesa unos cambios que cuestionan la disolución de los roles y usos tradicionales del Arte, y continúa rompiendo las barreras que lo delimitan de otros ámbitos.

Se procede así a la transmisión de una memoria basada en el enclave de búsqueda de la comunicación, de la voluntad de saber y no olvidar, de tendencia a la participación en cuestiones que atañen a una colectividad y un espacio de todos y todas y para todos y todas. La respuesta ejecutada en el seno de las ciudades a través de la monumentalidad (no exclusivamente en cuestiones de recuperación de la memoria histórica) supone la necesaria reflexión sobre nuevas formas de conmemoración y de emplazamiento de propuestas de dignificación y re-significación de espacios de memoria, así como el caer en la cuenta de la transversalidad de las intervenciones y en la monumentalización de áreas alejadas del centro nuclear urbano, pues en ellas reside asimismo una memoria conformadora de identidad.

Félix Duque (2011) señalaba, en referencia al arte urbano y el espacio público, a grupos que pecan de «paternalismos» al llevar a cabo un arte para el ciudadano pero sin el ciudadano, o grupos que más que realizar prácticas materiales que continúen elaborando un discurso visual, inciden en el terreno más sociológico de relación con la ciudadanía. También Henri Lefebvre (1974), por otro lado, describía que ciertas prácticas, con el fin de dar visibilidad a la memoria histórica en el espacio público mediante información $\mathrm{y}$ «texto», pierden la capacidad de producir una «textura» que realmente confiera un simbolismo al espacio donde es pretendido realizar una re-significación de la memoria. Es así que por un lado podemos observar que existe la necesidad de implicar a grupos sociales en el seno de la elaboración de este 
tipo de obras, de alejarse del arte transmisor de grupos hegemónicos, que se precisa recuperar la memoria histórica del lugar mediante testimonios, documentos, archivos, pero, por otro lado, las propias intervenciones en el espacio público deben aportar una calificación del territorio, materializaciones que desde una mirada de interpelación social, ofrezcan símbolos que aporten una imagen a la que acogerse para el acto de recordar. La imagen de la memoria.

Y son especialmente susceptibles aquellos espacios que han presenciado dramas humanos. Merecen ser tenidas en cuenta las distintas dimensiones que participan a la hora de una resignificación; por su carga simbólica; por su impronta en el territorio como estructura diferenciada en el dibujo de la trama urbana; por la multiplicidad de sensibilidades que despiertan los hechos; por el aspecto más político e ideológico inherente a la represión que viene dada por una situación de opresión dirigida desde un foco muy concreto y hegemónico; por el riesgo de la banalización en el discurso conmemorativo, y por el riesgo de la censura de contenidos a la hora de activar mecanismos de transmisión a través de distintos lenguajes, como sucedió en los intentos de exposición de la investigación del artista Francesc Abad sobre la memoria del Camp de la Bota (Barcelona), o como es el caso de la intervención parcialmente censurada en el espacio recuperado de la cárcel Modelo de Barcelona.

Y no sólo reside aquí el conflicto, sino también en qué prácticas son capaces de albergar memorias que no irrumpan anárquicamente en el espacio por mucho que sean de autoría colectiva, por mucho que cuenten con un estudio del entorno urbano, por mucho que recuperen subjetividades silenciadas pero necesarias, o por muy apoyadas que sean por las autoridades, pues la legitimidad de las intervenciones no les será conferida exclusivamente por las miradas activas en el proceso, sino por los habitantes y usuarios de un espacio común y público donde han de caber todos y todas. Es por ello por lo que la temática puede presentar puntos de fuga que entran en juego con un factor todavía más extenso: su vigencia o permanencia en el tiempo. Aquellas intervenciones que en sí mismas tratan sobre la memoria, «un concepto relacional y temporal» como David Harvey indicaba, llevan intrínseco el aspecto del transcurrir del tiempo, y en ellas ha de presentarse un pasado que importe en el presente para caminar hacia el futuro, pero además ha de valorarse la posible mutación de su contenido y forma en un período posterior a la contemporaneidad, en el 
que la sociedad evolucione y se transforme su mentalidad y percepción del mundo. La obsolescencia es algo a lo que atenerse. Así pues, ¿cómo realizar una intervención que mantenga vigente su sentido y su lenguaje cuando las preocupaciones sean otras y cuando otra actualidad modifique la lectura de los códigos de la transmisión y los medios del arte público?

Es aquí donde el concepto de heterotopía de Foucault vuelve a tener presencia. Los tipos de espacios que venimos desarrollando contienen entrelazamientos de diferentes dimensiones urbanas, simbólicas, culturales, sociales, territoriales, históricas, funcionales, etc.; también de diferentes agentes urbanos; o de vinculaciones con otros espacios análogos; pero además, la temporalidad asiste al término proponiendo una perspectiva múltiple y no exclusiva del factor tiempo, pues, si veíamos que no se trata de una gradación, y el pasado y presente no se rigen por un estricto antes y después, tampoco ha de obviarse que un momento de la actualidad puede hallarse vinculado a otros de la historia, tomando diferentes referencias de expresión y de actuación, y confiriendo sentidos mutables con la actualidad. Contra-emplazamientos que lejos de asumir roles permanentes y específicos muestran (y esconden) muchas líneas de latitud.

Se subraya el carácter del proceso como producto en sí mismo, capaz de incidir en la transformación del espacio público con pequeñas intervenciones que van desde la celebración del espacio, hasta la incursión en la esfera pública.

$\mathrm{Si}$, como afirma Bronislaw Baczko, toda ciudad es, entre otras cosas, una proyección de los imaginarios sociales sobre el espacio, las marcas que los esfuerzos de memorialización estampan en la superficie urbana componen un texto privilegiado donde se leen las valoraciones e interpretaciones colectivas de las memorias. En su modo de desplegarse en el espacio puede detectarse el grado de consenso o conflicto que subyace a los relatos sobre el pasado así como las tensiones que atraviesan el presente. Éstos se ponen en juego no sólo en las posiciones y discusiones que atañen a los objetos destinados a la conmemoración y el recuerdo sino también, o sobre todo, en las prácticas asociadas a esos objetos o sitios del recuerdo, trátese de una plaza, una calle, un monumento o un antiguo sitio de ejecución o centro de detención y/o tortura. (Schindel, 2009) 
Las cuestiones formales buscan la inmersión en un lenguaje visual contemporáneo, inteligible por el usuario, presente en las nuevas tecnologías tanto digitales como industriales, para emplazarse en el espacio público entendiendo su estructura horizontal y vertical, así como los elementos ya existentes. Monumentos-forma que se adapten a los enclaves visuales del siglo XXI regido por los medios de comunicación y la publicidad. En un momento histórico en el que el ser humano es estimulado con cantidades incomprensibles de información, el reto reside en cómo hacer que el espacio público no se convierta en otra plataforma virtual cargada de pestañas emergentes, pero abriendo la oportunidad a que memorias e identidades colectivas que todavía no son públicas, hallen su lugar de incursión.

Sin embargo, observamos que la práctica artística puede ver incluida dentro de sus estrategias de actuación, la dotación de equipamientos, o la intervención urbana, cuando se trata de espacios de gran complejidad. Ésta comienza a localizarse como un modo de hacer cada vez más circunscrito en la transversalidad y aparentemente más versátil para una sociedad que practica transformaciones (aunque polarizadas) veloces, y perpetúa una búsqueda de lenguajes que puedan sostener nuevos (re)significados.

\section{Referencias}

Ajuntament de Barcelona. (2009). Criteris i continguts per a la redacció del pla director de transformació de la presó Model de Barcelona. Abril 2009. Barcelona.

Ayuntamiento de Segovia. Segovia Centro de Creación. Recuperado de http://www.lacarceldesegovia.com/

Armajani, S. (1995). «El arte público en el contexto de la democracia americana». En: vvaA (1999), Siah Armajani. Madrid: Museo Nacional de Arte Reina Sofía.

Brandão, P. (2011). La imagen de la ciudad. Estrategias de identidad y comunicación Barcelona. Barcelona: Publicaciones Universidad de Barcelona.

Butler, J. (2000). «¿Qué es la crítica? Un ensayo sobre la virtud de Foucault». En vVAA (2008), Producción cultural y prácticas instituyen- 
tes. Líneas de ruptura en la crítica institucional. Madrid: Traficantes de sueños.

Cabrera i Massanés, P. (2007). Ciutat Vella de Barcelona. Memòria d'un procés urbà. Barcelona: Ara Libres.

Crespo, B. (2016). «Arte participativo en el espacio público. Proposiciones metodológicas acerca de algunos de sus preceptos». On the W@terfront. Vol 45, n. 2. July 1st. Recuperado de http://www.ub.edu/escult/Water/ water45_2/water45_2_TOTAL.pdf

Debray, R. (1999). «Trace, Forme, Message». Les Cahiers de médialogie, nº 7 , La Confusion des Monuments, pp. 27-44.

Duque, F. (2011). «Arte urbano y espacio público». Res publica, 26, pp. 7593. Recuperado de https://revistas.ucm.es/index.php/RPUB/article/ viewFile/47834/44764

Fontova, R. (2010). La Model de Barcelona. Històries de la Presó. Barcelona: Generalitat de Catalunya.

Foucault, M. (1967). Espacios diferentes en: Estética, ética y hermenéutica. Barcelona: Paidós (1999), pp.431-441.

Grandas, C. y Remesar, A. (2008). «Arte Público, Espacio Público y Memoria». Ponencia presentada por la Dra. Carme Grandas en los II Diálogos Permanentes de Arte en la Calle, Venezuela. Sede IARTES, Caracas, y Centro de Arte de Maracaibo Lía Bermúdez, Maracaibo. Julio-agosto 2008. Recuperado de https://www.academia. edu/5965212/Arte_público_espacio_público_y_memoria

Halbwachs, M. (1925). Marcos sociales de la memoria. Madrid: Anthropos (2004).

Harvey, D. (2003). Paris, Capital of Modernity. New York and London: Routledge.

Huyssen, A. (2001). En busca del futuro perdido. Cultura y memoria en tiempos de globalización. Buenos Aires: Fondo de cultura económica de Argentina. Recuperado de https://es.scribd.com/doc/218106129/ Huyssen-Andreas-2001-En-busca-del-futuro-perdido-Cultura-y-memoria-en-tiempos-de-globalizacion

Jordan, L. (2006). «La cárcel y el parque: la transformación de la Ex-cárcel de Valparaíso en centro cultural». Bifurcaciones, núm. 6, otoño 2006. World Wide Web document, ISSN 0718-1132. Recuperado de http://www.bifurcaciones.cl/006/carcelyparque.htm

Krauss, R. (1978). «Sculpture in an expanded field». En H. Foster (ed.), The AntiAesthetic: Essays on Postmodern Culture. Seattle: Bay Press (1993). 
Lacy, S. (ED.). (1995). Mapping the terrain, New Genre Public Art Seattle. Washington: Bay Press.

LECEA, I. DE (2006). «Ignasi de Lecea "in memoriam"». On the waterfront, núm. 8 april, 2006. Recuperado de http://www.ub.edu/escult/Water/ index.htm

- Remesar, A. y Grandas, C. (2004). «Sistema de Información del arte público del Ayuntamiento de Barcelona». En línea. Barcelona: Ajuntament de Barcelona - Universitat de Barcelona. Recuperado de http://www.bcn.cat/artpublic

Lefebvre, H. (1974). La production de l'espace. Paris: Anthropos (2000).

Memorial Democràtic de Catalunya. (s. f.) «Espais de Memòria». Recuperado de http://memorialdemocratic.gencat.cat/ca/espais_de_la_ memoria/

Nora, P. (1984). «Between Memory and History: Les Lieux de Mémoire». Representations, núm. 26, Special Issue: Memory and Counter-Memory, pp. 7-24. Recuperado de http://cholonautas.edu.pe/memoria/ nora1.pdf

Parque Cultural de Valparaíso. (consulta 23/09/2016). Recuperado de http://parquecultural.cl/

Plataforma Fem nostre l'Espai de la Model. «Plataforma ciudadana». Recuperado de https://presomodel.wordpress.com/

Plataforma Futur Monument a la Presó de Dones de Les Corts. Recuperado de http://blocs.lescorts.cc/presodedones/

Perejaume (2015). Paraules locals. Barcelona: Tushita.

Remesar, A. (1997). Hacia una Teoría del Arte Público. Barcelona: Universidad de Barcelona.

— (2016a). «Arte público. Retos y oportunidades (I). La emergencia de nuevos lenguajes». On the W@terfront, vol.41,núm.1. Enero. Recuperado de http://www.raco.cat/index.php/Waterfront/issue/view/23337

- (2016c). ¿Monuments Vs. Memorials? Some doubts, some reflections. No proposals? Barcelona: Publicaciones de la Universidad de Barcelona, pp. 55-90. Recuperado de http://www.academia. edu/23900888/2016.-_MONUMENTS_vs_MEMORIALS_Some_ doubts_some_reflections._No_proposals

Remesar, A. y Ricart, N. (2010). «Arte público». Ar@cne. Revista electrónica de recursos en Internet sobre Geografia y Ciencias Sociales. Barcelona: Universidad de Barcelona, $\mathrm{n}^{\circ}$ 132, 1 de abril de 2010. Recuperado de http://www.ub.es/geocrit/aracne/aracne-132.htm 
- (2013a). «Estrategias de la Memoria. 1977-2011. Memoria Histórica en Barcelona, España». Comunicación aprobada para la 16 Convención Científica de Ingeniería y Arquitectura, CUJAE, La Habana, del 26 al 30 de noviembre de 2012.

- (2013b). «Estrategias de la Memoria. Barcelona, 1977-2013». Scripta Nova. Revista Electrónica de Geografía y Ciencias Sociales, VOL. XVIII, $\mathrm{n}^{\mathrm{o}}$ 495. Barcelona: Universidad de Barcelona, 20 de noviembre de 2014. Recuperado de http://www.ub.es/geocrit/sn/sn-495.htm

Ricart, N. (2012). «El lugar de la memoria». On the W@terfront, núm. 22, Universitat de Barcelona. Recuperado de http://www.raco.cat/index.php/Waterfront/article/view/252042

- Guixé, J. (EDS.) (14 abril 2015). «Futur monument a la presó de dones de Les Corts. Procés obert». On the W@terfront, vol. 36, núm. 1. Recuperado de http://www.ub.edu/escult/Water/water36_1/water36_1_04.pdf

Salvemos Carabanchel (s. f.). «Plataforma por un Centro para la paz y la memoria en la antigua cárcel de Carabanchel». Recuperado de http://salvemoscarabanchel.blogspot.com.es/

Sitios de Memoria en América Latina. (s. f.). «Red latinoamericana de sitios de conciencia». Recuperado de http://www.sitiosdememoria.org/

SCHINDEL, E. (2009). «Inscribir el pasado en el presente: memoria y espacio urbano». Política y Cultura, núm. 31, pp. 65-87. Universidad Autónoma Metropolitana Unidad Xochimilco Distrito Federal México DF Recuperado de http://www.redalyc.org/articulo. oa? id $=26711982005$ 